\title{
Airway Mucus Hyperconcentration in Non-Cystic Fibrosis Bronchiectasis
}

\author{
Kathryn A. Ramsey ${ }^{1,2}$, Alice C. H. Chen ${ }^{3,4}$, Giorgia Radicioni ${ }^{1}$, Rohan Lourie ${ }^{3,5}$, Megan Martin ${ }^{6}$, Amy Broomfield ${ }^{5}$, \\ Yong H. Sheng ${ }^{3}$, Sumaira Z. Hasnain ${ }^{3}$, Graham Radford-Smith ${ }^{7}$, Lisa A. Simms ${ }^{8}$, Lucy Burr ${ }^{3,6}$, David J. Thornton ${ }^{9}$, \\ Simon D. Bowler ${ }^{6}$, Stephanie Livengood ${ }^{1}$, Agathe Ceppe ${ }^{1}$, Michael R. Knowles ${ }^{1}$, Peadar G. Noone, Sr. ${ }^{1}$, \\ Scott H. Donaldson ${ }^{1}$, David B. Hill ${ }^{1,10}$, Camille Ehre ${ }^{1}$, Brian Button ${ }^{1}$, Neil E. Alexis ${ }^{11}$, Mehmet Kesimer ${ }^{1 *}$, \\ Richard C. Boucher ${ }^{1 *}$, and Michael A. McGuckin ${ }^{3,12 *}$ \\ ${ }^{1}$ Marsico Lung Institute, ${ }^{10}$ Department of Physics and Astronomy, and ${ }^{11}$ Center for Environmental Medicine, Asthma and Lung Biology, \\ University of North Carolina at Chapel Hill, Chapel Hill, North Carolina; ${ }^{2}$ Department of Pediatrics, Pediatric Respiratory Medicine, \\ Bern University Hospital, University of Bern, Bern, Switzerland; ${ }^{3}$ Inflammatory Disease Biology and Therapeutics Group, Mater \\ Research Institute, Translational Research Institute, and ${ }^{4}$ School of Medicine, University of Queensland, Brisbane, Queensland, \\ Australia; ${ }^{5}$ Department of Anatomical Pathology, Mater Misericordiae Limited, South Brisbane, Queensland, Australia; ${ }^{6}$ Department of \\ Respiratory Medicine, Mater Adult Hospital, South Brisbane, Queensland, Australia; ${ }^{7}$ Inflammatory Bowel Diseases Research \\ Laboratory, Royal Brisbane and Women's Hospital, Herston, Queensland, Australia; ${ }^{8}$ Inflammatory Bowel Diseases Research \\ Laboratory, Queensland Institute of Medical Research, Brisbane, Queensland, Australia; ' Wellcome Trust Centre for Cell-Matrix Research, \\ Lydia Becker Institute for Immunology and Inflammation, Faculty of Biology, Medicine and Health, University of Manchester, Manchester, \\ United Kingdom; and ${ }^{12}$ Faculty of Medicine, Dentistry and Health Sciences, University of Melbourne, Melbourne, Victoria, Australia
}

ORCID ID: 0000-0001-7148-1970 (D.J.T.).

\section{Abstract}

Rationale: Non-cystic fibrosis bronchiectasis is characterized by airway mucus accumulation and sputum production, but the role of mucus concentration in the pathogenesis of these abnormalities has not been characterized.

Objectives: This study was designed to: 1) measure mucus concentration and biophysical properties of bronchiectasis mucus; 2) identify the secreted mucins contained in bronchiectasis mucus; 3 ) relate mucus properties to airway epithelial mucin RNA/protein expression; and 4) explore relationships between mucus hyperconcentration and disease severity.

Methods: Sputum samples were collected from subjects with bronchiectasis, with and without chronic erythromycin administration, and healthy control subjects. Sputum percent solid concentrations, total and individual mucin concentrations, osmotic pressures, rheological properties, and inflammatory mediators were measured. Intracellular mucins were measured in endobronchial biopsies by immunohistochemistry and gene expression. MUC5B (mucin 5B) polymorphisms were identified by quantitative PCR. In a replication bronchiectasis cohort, spontaneously expectorated and hypertonic saline-induced sputa were collected, and mucus/mucin concentrations were measured.

Measurements and Main Results: Bronchiectasis sputum exhibited increased percent solids, total and individual (MUC5B and MUC5AC) mucin concentrations, osmotic pressure, and elastic and viscous moduli compared with healthy sputum. Within subjects with bronchiectasis, sputum percent solids correlated inversely with $\mathrm{FEV}_{1}$ and positively with bronchiectasis extent, as measured by high-resolution computed tomography, and inflammatory mediators. No difference was detected in MUC5B rs35705950 SNP allele frequency between bronchiectasis and healthy individuals. Hypertonic saline inhalation acutely reduced non-cystic fibrosis bronchiectasis mucus concentration by $5 \%$.

Conclusions: Hyperconcentrated airway mucus is characteristic of subjects with bronchiectasis, likely contributes to disease pathophysiology, and may be a target for pharmacotherapy.

Keywords: mucin; induced sputum; gene expression

(Received in original form June 21, 2019; accepted in final form November 22, 2019)

${ }^{*}$ Co-senior authors.

This study was funded by Mater Adult Respiratory Research Trust Fund, Mater Foundation, NIH (R01 HL136961, 5 P30 DK 065988-13, P01 HL108808, and UH2/UH3 HL123645), and Cystic Fibrosis Foundation grant BOUCHE15RO. K.A.R. was supported by the National Health and Medical Research Council of Australia (APP1088389) and Swiss National Science Foundation (PZOOP3-168173). D.J.T. was supported by grant THORNT07XXXO. The funders had no role in study design, data collection and analysis, decision to publish, or preparation of the manuscript.

Author Contributions: K.A.R., A.C.H.C., R.L., M.K., R.C.B., and M.A.M. designed the study. All authors undertook study-related procedures. K.A.R., A.C.H.C., and M.M. collected the data. K.A.R., A.C.H.C., R.L., Y.H.S., S.Z.H., L.B., D.J.T., A.C., M.R.K., P.G.N., D.B.H., C.E., B.B., and M.A.M. analyzed and interpreted the data. K.A.R., A.C.H.C., R.C.B., and M.A.M. wrote the paper, and all authors reviewed and revised the paper. All authors approved the final version.

Correspondence and requests for reprints should be addressed to Richard C. Boucher, M.D., Marsico Lung Institute, University of North Carolina at Chapel Hill, 125 Mason Farm Road, Chapel Hill, North Carolina 27599. E-mail: richard_boucher@med.unc.edu.

This article has a related editorial.

This article has an online supplement, which is accessible from this issue's table of contents at www.atsjournals.org.

Am J Respir Crit Care Med Vol 201, Iss 6, pp 661-670, Mar 15, 2020

Copyright $\odot 2020$ by the American Thoracic Society

Originally Published in Press as DOI: 10.1164/rccm.201906-12190C on November 25, 2019

Internet address: www.atsjournals.org 


\section{At a Glance Commentary}

\section{Scientific Knowledge on the \\ Subject: Non-cystic fibrosis} bronchiectasis (NCFB) is a chronic airways disease characterized by sputum production, persistent airway inflammation, and repeated episodes of disease exacerbation. Although daily sputum volume and $\mathrm{FEV}_{1}$ may be indicators of disease severity in NCFB, the roles of mucus concentration and biophysical properties in disease pathogenesis have not been elucidated.

\section{What This Study Adds to the Field:}

This study characterized the concentration and biophysical properties of sputum from subjects with NCFB. NCFB sputa were excessively concentrated compared with healthy control subjects, with higher percent solids and total mucin concentrations. The biophysical properties of NCFB sputa, for example, osmotic pressures and elastic and viscous moduli, were also increased and positively correlated with sputum concentration. MUC5B was the dominant mucin raised in NCFB sputum, with modest total elevations in MUC5AC but little MUC2. The magnitudes of the increases in mucus concentration and biophysical values suggest that mucus hyperconcentration contributes to defective mucus clearance and disease pathogenesis in NCFB and may be a target for therapy.

Non-cystic fibrosis bronchiectasis (NCFB) is characterized by persistent production of purulent sputum, irreversible airway dilatation, inflammation, and bacterial infection. NCFB is commonly observed in the middle and lower lobes, reflecting a failure of mucociliary clearance and gravity-dependent mucus accumulation (1). NCFB can manifest as early and severe mucopurulent obstruction in the small airways, which can be difficult to recognize radiographically (2). The pathogenesis of the underlying mucus overproduction, inflammation, and region-specific airway damage in NCFB is poorly understood.

A unifying description of lung mucus clearance in health and disease has emerged that identifies mucus concentration as central to mucoobstructive disease pathogenesis (3). The "two-gel" hypothesis predicts that when the concentration of the mucus layer containing the secreted mucins (MUC5B [mucin 5B] and MUC5AC) exceeds that of the tethered mucindominated periciliary layer (PCL), osmotic compression of the cilia results (4). This state produces mucus stasis and a positive feedback cycle of inflammation and mucus secretion (5). Recent studies have demonstrated that the mucus concentration, and proportionally mucin concentration, of cystic fibrosis (CF) sputum is on average threefold higher than normal sputum $(6,7)$. The concentration of mucins is also elevated in sputum samples from subjects with chronic obstructive pulmonary disease (COPD) and correlates with increased disease severity and chronic bronchitis symptoms (8). These and other studies also established that the elevated mucus concentrations of COPD and CF are dominated by increases in MUC5B (7-9). The only study of NCFB sputum mucin content reported an unexpectedly high concentration of the intestinal mucin MUC2, less MUC5AC, and very little MUC5B (10). Therefore, whether abnormal airway mucus concentration or mucin species expression is inherent to the pathogenesis of NCFB is unclear.

Accordingly, we comprehensively characterized sputum collected after hypertonic saline (HS) induction from the BLESS (Bronchiectasis and Low-Dose Erythromycin Study) NCFB cohort, composed of subjects with relatively severe bronchiectasis (11), and compared these data with healthy control subjects. The first aim was to investigate whether mucus concentration and biophysical properties, including sputum percent solids, total mucin concentration, osmotic pressure, and elastic and viscous moduli, in BLESS sputa were in ranges predicted to impair mucus clearance. The second aim was to measure the percent solids and total mucin concentration in a replicate NCFB cohort and compare concentrations of spontaneously expectorated sputum with sputum induced by HS inhalation. The third aim was to measure the relative concentrations of MUC5B, MUC5AC, and MUC2 in NCFB versus control sputum. The fourth aim was to relate mucus properties to airway mucin RNA/protein expression. Finally, we explored relationships between the mucus concentration data and data available in the BLESS cohort describing NCFB disease severity, cytokines, and MUC5B genotypes. Some of the results of these studies have been previously reported in the form of abstracts $(12,13)$.

\section{Methods}

\section{Subjects and Procedures}

Full details of the methods are provided in the online supplement. This study was approved by Mater Health Services (HREC 1244A) and University of North Carolina at Chapel Hill (UNC) (\#16-3142)

Human Research Ethics Committees, and all subjects provided written informed consent. In total, 117 subjects with NCFB enrolled in the BLESS study, who were extensively characterized with spirometry, high-resolution CT, and questionnaires (e.g., St. George's Respiratory Questionnaire), had HSinduced sputum collected and immediately aliquoted and frozen at $-80^{\circ} \mathrm{C}$ after discarding the material obtained during the first $5 \mathrm{~min}$ of induction to reduce salivary contamination (11). A subgroup of 34 BLESS subjects underwent bronchoscopy (11). Twenty healthy control subjects recruited from the community in Queensland, Australia, also underwent identical HS sputum induction and bronchoscopy. Sputum samples collected midway through the trial from 99 subjects with NCFB were sent to UNC for mucus analysis.

As a replication cohort, 15 subjects with NCFB were recruited from the UNC Bronchiectasis Centre, and 15 healthy control subjects were recruited from the local community in North Carolina. Matched HS-induced and spontaneously expectorated sputum were collected from the subjects with NCFB in the UNC NCFB cohort. HS-induced sputum only could be collected from the UNC healthy subjects.

\section{Mucus Percent Solids and Total, Individual Mucin, and DNA Concentrations}

The percentage of mucus solid content, an index of hydration, was calculated by measuring dry-to-wet weight ratio of $25 \mu \mathrm{l}$ aliquots of sputum in triplicate using an ultramicrobalance (UMX2; Mettler Toledo) (4). Sputum total mucin concentrations 
were measured by HPLC and refractometry methods as previously reported (7).

Absolute concentrations of MUC5AC, MUC5B, and MUC2 were measured by labeled mass spectrometry in a subset of sputum samples $(n=33)(8)$. To assess the charge status of MUC5AC and MUC5B, agarose gel Western blotting was performed (14). The DNA concentration of sputum was quantified using a Quant-iT PicoGreen dsDNA Assay Kit (ThermoFisher Scientific).

\section{Mucus Osmotic Pressure and Rheology}

Sputum osmotic pressures were measured using a custom-designed direct membrane colloid osmometer incorporating a $10-\mathrm{kD}$ membrane as previously described (4). The viscous and elastic moduli of sputum were determined by cone and plate rheology as previously reported (15).

\section{MUC5AC and MUC5B \\ Immunohistochemistry}

Immunohistochemistry of

transbronchoscopic biopsies for MUC5AC and MUC5B was performed as described previously (16). A score from 0 to 4 was assigned to the surface epithelium and submucosal glands according to the percentage of mucin-positive cells: $0=$ no staining, $1=1-25 \%, 2=26-50 \%$, $3=51-75 \%$, and $4=76-100 \%$.

\section{Gene Expression}

Gene expression was measured in RNA extracted from airway biopsies by quantitative PCR. Details are provided in the online supplement.

\section{MUC5B Promoter SNP Genotyping Assay}

MUC5B promoter SNP (rs35705950) genotype was determined using a TaqMan SNP Genotyping Assay (Life Technologies). Healthy individuals $(n=575)$ were randomly selected from the Queensland electoral roll.

\section{Data Analysis}

Data analysis for the BLESS clinical trial has been described previously (11). As the primary focus of this study was to examine associations between mucus properties and clinical outcomes in NCFB, data from the placebo and treatment arms were grouped. Mann-Whitney $U$ and Kruskal-Wallis tests were used to test the significance of variance between control and disease groups. For paired group comparisons, Wilcoxon signed- rank tests were used. Results are presented in median and interquartile range, and correlations are presented with 95\% confidence interval, unless specified otherwise. Correlations were calculated using Spearman rho correlation coefficients. Receiver operating characteristic curve analysis was utilized to test the ability of mucus properties to predict NCFB. Statistical analyses were performed using STATA (version 13.1) and GraphPad Prism (version 7) software, where $P$ values $<0.05$ were considered significant.

\section{Results}

The demographic information for the NCFB and healthy control subjects from the BLESS and UNC cohorts is provided in Table 1. The demographics for the full BLESS cohort are provided in Table E1 in the online supplement.

\section{Mucus, Total Mucin, and DNA Concentration}

The mean mucus percent solids and total mucin concentrations were approximately threefold higher in sputum from individuals with NCFB than in healthy control subjects, respectively $(P<0.001)$ (Figures $1 \mathrm{~A}$ and $1 \mathrm{~B}$ and Table 1). Total DNA concentrations were $\sim 20$-fold higher in subjects with NCFB than in control subjects (Figure 1C). However, DNA concentrations were $\sim 13$-fold lower than total mucin concentrations in subjects with NCFB $(P<0.001)$. Total mucin (Spearman rho $[95 \%$ confidence interval $]=0.81[0.73-0.88]$, $P<0.001)$ and DNA concentrations $(0.72$ [0.60-0.84], $P<0.001)$ positively correlated with mucus percent solids in patients with NCFB (Figures 1D and 1E). Daily sputum volume did not correlate with mucus percent solids (Figure E1A), total mucin concentration, or total DNA concentration.

\section{Reproducibility of NCFB Mucus Concentration and Effect of HS Induction}

The mucus percent solids (Figure 2A) and total mucin content (Figure $2 \mathrm{~B}$ ) were not different between HS-induced sputum samples from BLESS and UNC subjects with NCFB (also Table 1). However, sputum induction with HS reduced the percent solids and total mucin concentration $\sim 25 \%$ compared with spontaneous sputum samples collected in the same UNC subjects with NCFB (Figure 2).

Table 1. Subject Demographics and Disease Characteristics of Patients with Non-Cystic Fibrosis Bronchiectasis and Healthy Individuals Included in the Study

\begin{tabular}{|c|c|c|c|c|}
\hline & \multicolumn{2}{|c|}{ BLESS } & \multicolumn{2}{|c|}{ UNC } \\
\hline & Bronchiectasis & Healthy & Bronchiectasis & Healthy \\
\hline \multicolumn{5}{|l|}{ Demographics } \\
\hline$n$ & 99 & 20 & 15 & 15 \\
\hline Age, yr, mean ( $\pm S D)$ & $62( \pm 10)$ & $36( \pm 12)$ & $66( \pm 13)$ & $42( \pm 19)$ \\
\hline Sex, F, No. (\%) & $59(60)$ & $12(60)$ & $13(86)$ & $12(80)$ \\
\hline \multirow{2}{*}{\multicolumn{5}{|c|}{$\begin{array}{l}\text { Lung function } \\
\text { measurements }\end{array}$}} \\
\hline & & & & \\
\hline $\mathrm{FEV}_{1}, \mathrm{~L}$, mean $( \pm \mathrm{SD})$ & $1.8( \pm 0.7)$ & $3.5( \pm 0.8)$ & $1.7( \pm 0.7)$ & $3.7( \pm 0.8)$ \\
\hline $\begin{array}{l}\mathrm{FEV}_{1}, \% \text { predicted, mean } \\
( \pm \mathrm{SD})\end{array}$ & $66( \pm 18)$ & $98( \pm 13)$ & $69( \pm 21)$ & $100( \pm 9)$ \\
\hline \multicolumn{5}{|l|}{ Sputum microbiology, No. (\%) } \\
\hline Normal flora (no pathogens) & $53(45)$ & $20(100)$ & $8(53)$ & NA \\
\hline$P$. aeruginosa & $41(35)$ & 0 & $3(20)$ & NA \\
\hline H. influenzae & $23(20)$ & 0 & $1(7)$ & NA \\
\hline S. maltophilia & $3(2.6)$ & 0 & $0(0)$ & NA \\
\hline Others & $5(4.3)$ & 0 & $3(20)$ & NA \\
\hline \multicolumn{5}{|l|}{$\begin{array}{l}\text { Mucus parameters, median } \\
\text { (interquartile range) }\end{array}$} \\
\hline Solids, \% & $2.7(2.0)$ & NA & $2.6(3.3)$ & $1.0(0.6)$ \\
\hline Total mucins, $\mu \mathrm{g} / \mathrm{ml}$ & $4,594(3,139)$ & NA & $3,951(2,770)$ & $1,820(1,954)$ \\
\hline Total DNA, $\mu \mathrm{g} / \mathrm{ml}$ & $279(482)$ & NA & 213 (619) & $9.2(20.1)$ \\
\hline Osmotic pressure, $\mathrm{Pa}$ & 439 (362) & NA & 420 (537) & $145(72)$ \\
\hline Complex viscosity, $\mathrm{Pa} \cdot \mathrm{s}$ & $0.2(0.3)$ & NA & $0.2(0.2)$ & $0.1(0.1)$ \\
\hline
\end{tabular}

Definition of abbreviations: BLESS = Bronchiectasis and Low-Dose Erythromycin Study; $H$. influenzae = Haemophilus influenzae; $N A=$ not applicable; $P$. aeruginosa $=$ Pseudomonas aeruginosa; S. maltophilia = Stenotrophomonas maltophilia; UNC = University of North Carolina at Chapel Hill. 
A
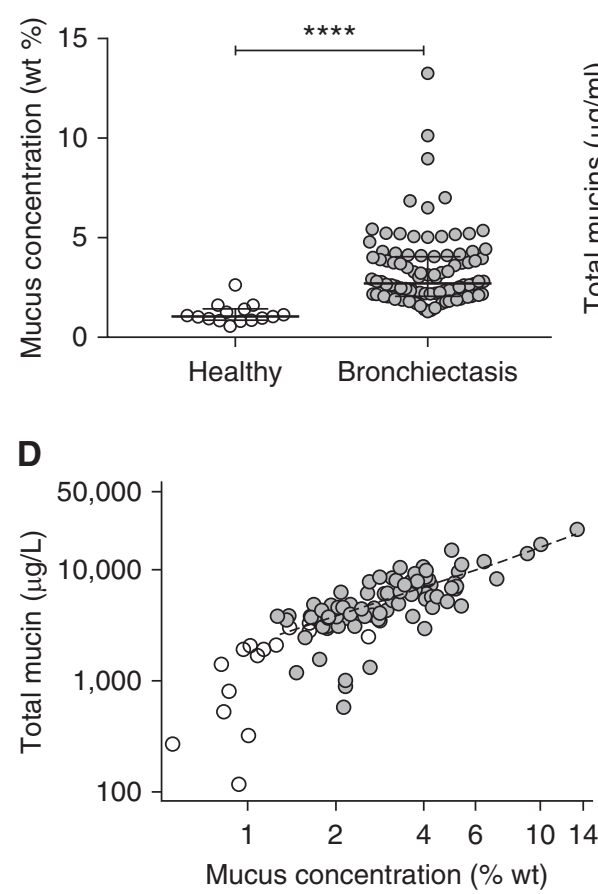

B

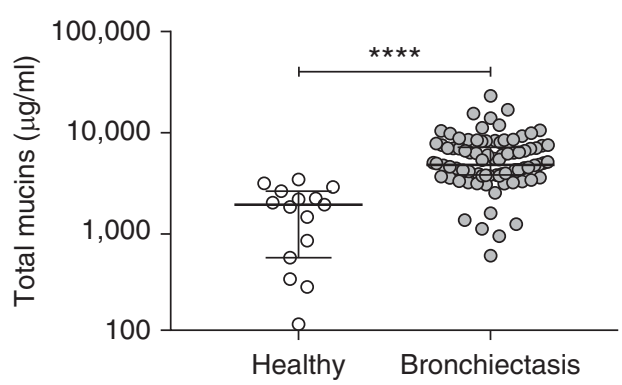

E

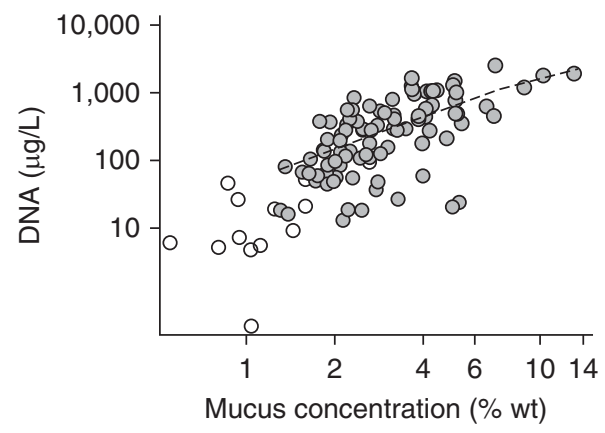

Figure 1. The biochemical properties of induced sputum from individuals with non-cystic fibrosis bronchiectasis (NCFB) and healthy control subjects. (A) Mucus percent solids, $(B)$ total mucin concentrations, and $(C)$ extracellular DNA concentration were each significantly higher in individuals with NCFB (gray circles) than in healthy control subjects (white circles). (D) Total mucin (Spearman rho [95\% confidence interval] $=0.81[0.73-0.88], P<0.001)$ and $(E)$ extracellular DNA concentrations (Spearman rho [95\% confidence interval] $=0.72$ [0.60-0.84], $P<0.001$ ) correlated significantly with mucus percent solids (NCFB: gray circles; control subjects: white circles). (A-C) Individual data points, median, and interquartile ranges are shown; Mann-Whitney nonparametric test was used. $n=99$ subjects with NCFB for all panels; $n=15$ healthy control subjects; ${ }^{* \star \star *} P<0.0001$. wt $=$ weight.

\section{Mucin Subtypes}

Mucin MUC5B concentrations were sixfold higher in subjects with NCFB than in healthy control subjects (Figure 3Ai). Absolute MUC5AC concentrations were 17 -fold higher in subjects with NCFB than in healthy control subjects (Figure 3Aii). The ratio of MUC5AC to MUC5B was approximately fourfold higher in subjects with NCFB $(0.37 \pm 0.05)$ than in healthy subjects $(0.1 \pm 0.03)$. Label-free proteomics revealed MUC2 concentrations were $\sim 100$ fold less than MUC5B or MUC5AC (Figure 3Aiii). With respect to isoforms, the low-charge isoform, but not high-charge isoform, of MUC5B was significantly higher in subjects with NCFB than in healthy subjects (Figures $3 \mathrm{~B}$ and $3 \mathrm{C}$ ).

\section{Sputum Biophysical Properties}

The osmotic pressure of sputum from healthy control subjects was $\sim 140 \mathrm{~Pa}$, similar to previously reported normal values (Figure $4 \mathrm{~A}$ ) (7). In contrast, the mean osmotic pressure of NCFB sputum was $\sim 550 \mathrm{~Pa}$, which was significantly greater than control subjects $(P<0.01)$. Sputum from patients with NCFB also had higher elastic modulus (3.0-fold), viscous modulus (2.8-fold), and complex viscosity (2.3-fold) than healthy sputum $(P<0.01$ each) (Figures 4B-4D). Sputum osmotic pressure (Spearman rho $[95 \%$ confidence interval $]=0.71[0.59-0.82], P<0.001)$ and complex viscosity $(0.49[0.32-0.66]$, $P<0.001)$ positively correlated with mucus percent solids (Figures $4 \mathrm{E}$ and $4 \mathrm{~F}$ ). Similarly, osmotic pressure and complex viscosity were positively associated with total mucin and DNA concentrations $(P<0.001$ each) (Figures E1B-E1E).

\section{Mucin Localization in Bronchial Biopsies}

In normal airways, scattered MUC5B staining was observed in the superficial epithelium in the absence of morphologic goblet cells (not shown) $(17,18)$. In contrast, mucus cells with a goblet cell morphology containing both MUC5AC and MUC5B were observed in NCFB superficial airway epithelia (Figure E2A).
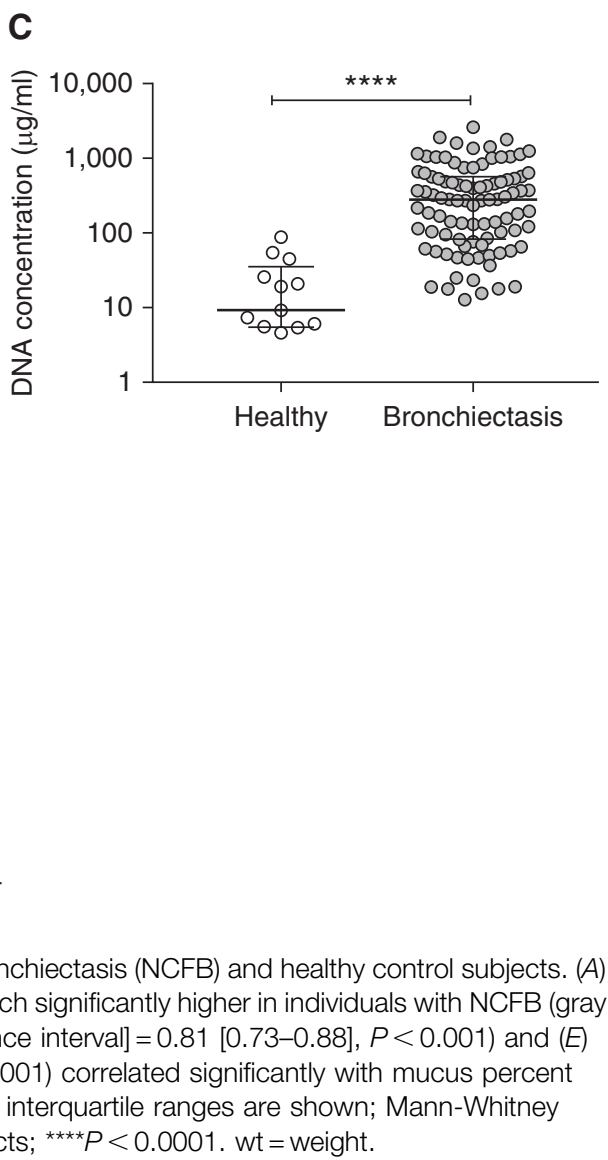

MUC5AC protein was not detected in the submucosal glands of the healthy or NCFB respiratory tract (Figure E2B). The proportion of surface epithelial cells expressing MUC5AC was significantly higher in NCFB than in healthy epithelium $(P<0.05)$ (Figure E2C). A trend to higher surface epithelial expression of MUC5B was observed in NCFB biopsies $(P=0.075)$.

\section{Expression of Mucin and Mucus Cell-Specific Genes}

Despite the elevated sputum concentrations of MUC5AC and MUC5B in subjects with NCFB, expression of MUC5AC and $M U C 5 B$ mRNA in NCFB endobronchial biopsies was not higher than healthy control subjects (Figure E3). MUC2 mRNA expression was low in healthy control subjects and significantly reduced in NCFB $(P<0.05)$, consistent with the low levels of MUC2 protein in NCFB sputum (Figure 3Aiii). The gene encoding a cell surface mucin, MUC4, was also downregulated in NCFB $(P<0.01)$, whereas there were no differences in 
A

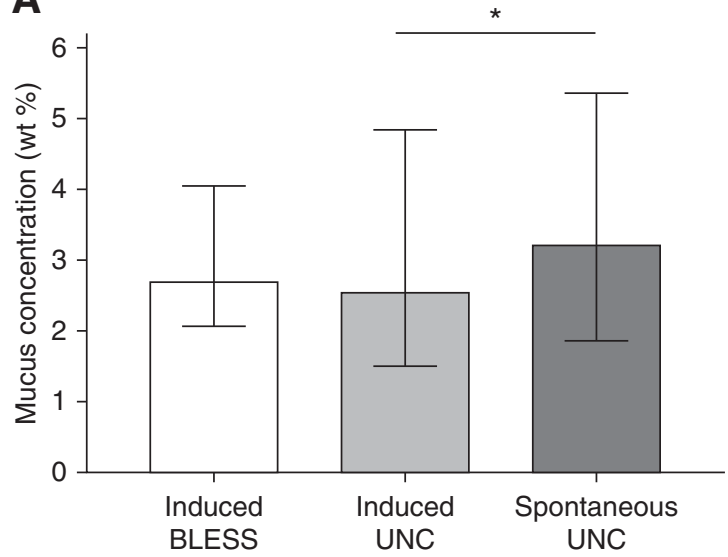

B

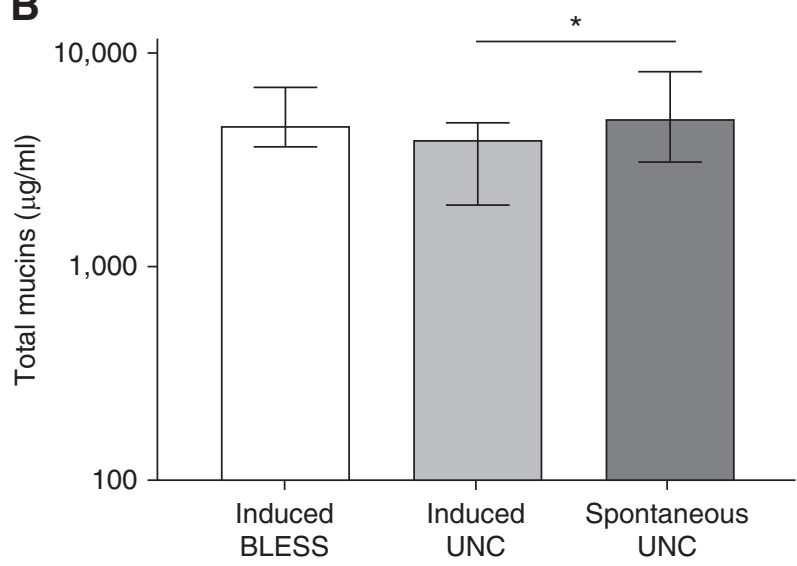

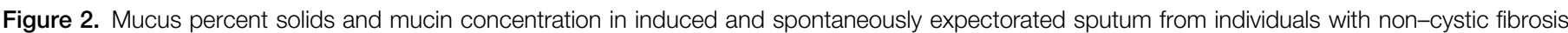

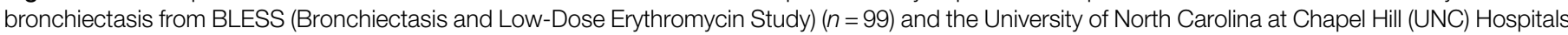

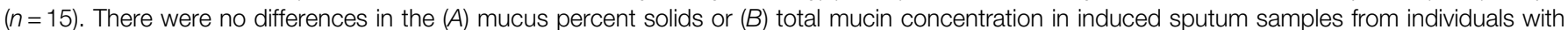

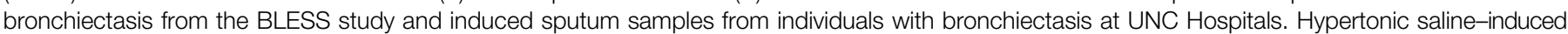

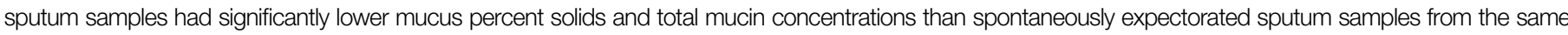

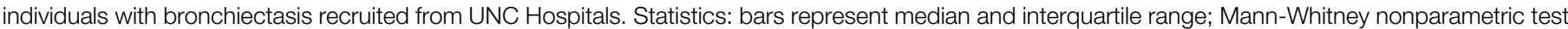
was used; ${ }^{\star} P<0.05$. wt $=$ weight.

expression of genes encoding the other major airway tethered mucins, that is, MUC1 and MUC16. Genes encoding proteins specifically expressed in mucinsecreting cells, for example, TFF1, TFF3, and $A G R 2$, were upregulated in subjects with NCFB compared with healthy control subjects (by sevenfold, threefold, and twofold, respectively), whereas expression of TFF2, SPDEF, and ZG16B was not significantly changed (Figure E3).

\section{IPF-associated MUC5B Polymorphism}

The IPF risk allele ( $\mathrm{T}$ ) frequency of rs35705950 in 101 BLESS subjects with NCFB did not differ from 575 population control subjects $(10.90 \%$ and $10.95 \%$, respectively) (Table E2). Within the NCFB cohort, carriage of the $\mathrm{T}$ allele was not associated with any sputum or clinical NCFB parameter.

\section{Association between Sputum Properties and Clinical Outcomes in NCFB}

The severe clinical features of the BLESS cohort are not representative of the broad NCFB populations and limit the sensitivity of exploratory analyses relating mucus properties to clinical parameters (11). However, associations of mucus properties were sought with respiratory symptoms (see online supplement) and clinical parameters obtained per the BLESS protocol.
Lung function and high-resolution chest computed tomography. Within BLESS subjects with NCFB, the $\mathrm{FEV}_{1}$ correlated inversely with high-resolution chest computed tomography (HRCT) bronchiectasis extent score, suggesting both describe NCFB severity (Figure 5A). Similarly, mucus concentration was inversely correlated with $\mathrm{FEV}_{1}$

(Figure 5B). Mucus concentration was positively correlated with the bronchiectasis extent score (Figure 5C), whereas daily sputum volume and mucus osmotic pressure were less strongly correlated with the bronchiectasis score (Table 2). No correlations were observed between total mucins, sputum volume, and $\mathrm{FEV}_{1}$ (not shown).

Inflammation. In subjects with NCFB, IL-8 and IL- $\beta$ concentrations and neutrophil elastase and matrix metalloproteinase activities were associated with sputum percent solids, total mucin concentration, MUC5AC/MUC5B ratio, daily sputum volume, $\mathrm{FEV}_{1}$, and HRCT scores (Figures 5D and 5E and Table 3).

Pathogens. NCFB sputum mucus and mucin concentrations were independent of cultured pathogenic microorganisms, including Pseudomonas aeruginosa (Figure E1F).

\section{Ability of Percent Solids to Predict NCFB}

ROC analysis was performed to test the ability of sputum percent solids to predict NCFB (Figure 5F). We generated an ROC for percent solids (continuous) utilizing data from all subjects with NCFB versus healthy control subjects. The area under the curve was 0.9603 . To determine the cutoff value for percent solids that maximized sensitivity and specificity, we used the Youden's index $($ sensitivity + specificity -1$)$, which yielded a percent solids value of $1.62 \%$.

\section{Discussion}

Dilated NCFB airways are characterized by the accumulation of inflamed mucus. Our study sheds light on the key constituents of NCFB mucus, its regulation, and relevance to NCFB pathogenesis. NCFB sputa were abnormally concentrated as evidenced by higher percent solids and total mucin concentrations than healthy subjects. These findings were replicated in a second NCFB cohort. Elevations in both MUC5B and MUC5AC airway mucins, but not MUC2, contributed to the raised percent solids/total mucin concentrations in the subjects with NCFB. Elevated mucus concentrations in NCFB were reflected in classic measures of sputum biophysical properties, including sputum viscosity, elasticity, and complex viscosity. Importantly, the increase in mucus concentration was also reflected in elevated mucus osmotic pressure in patients with NCFB.

Impairment of mucus transport occurs when the mucus layer osmotic pressure exceeds that of the PCL (4). The osmotic pressure values of the subjects with NCFB 
A

i

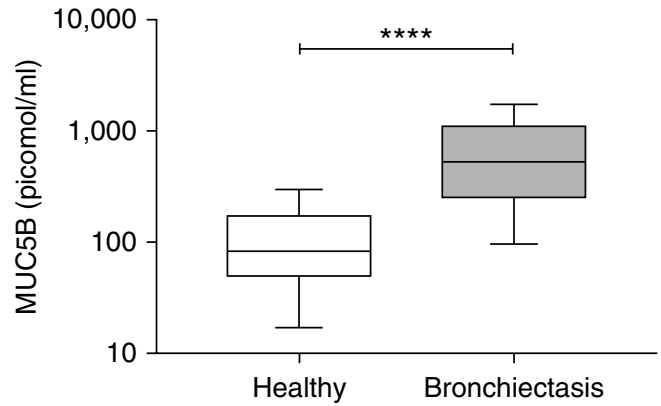

ii

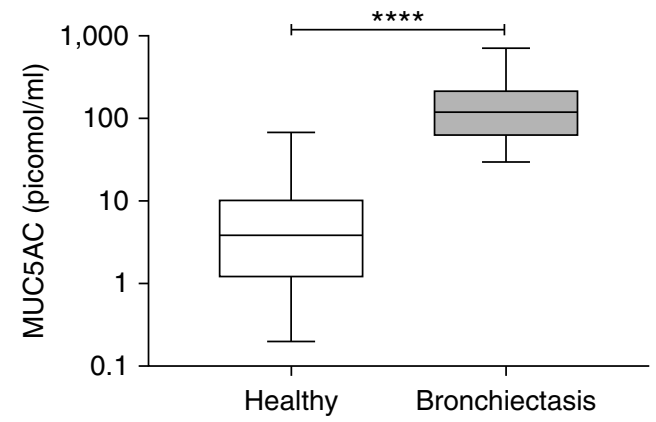

iii

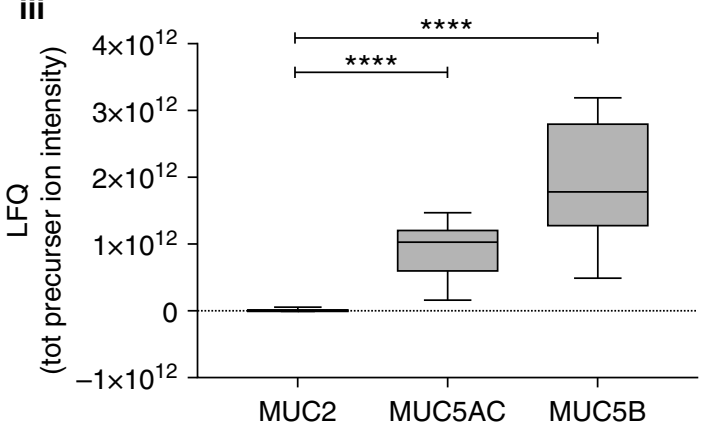

B

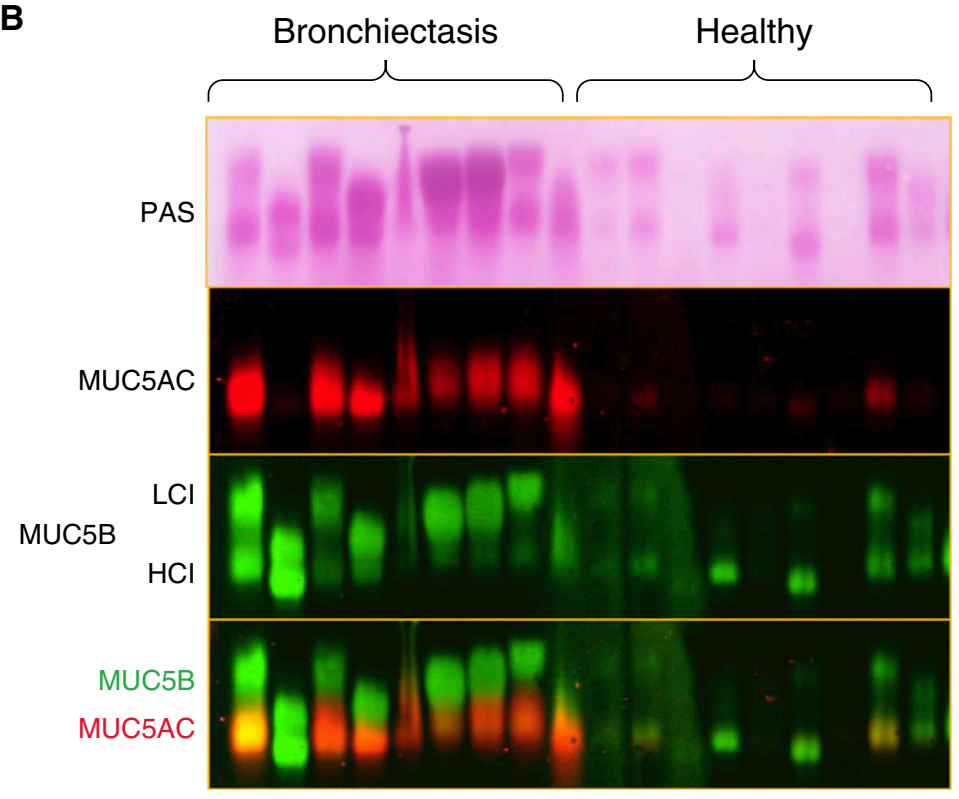

C

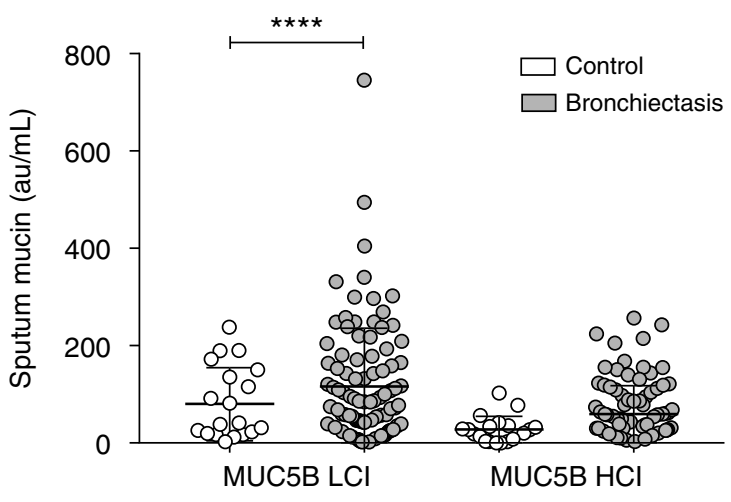

Figure 3. Mucin glycoproteins in induced sputum from individuals with non-cystic fibrosis bronchiectasis and healthy control subjects. (A) Quantification of MUC5B (mucin 5B) (Al) and MUC5AC (Aii) by internal standard labeled mass spectrometry and comparisons of MUC2 to MUC5AC and MUC5B by peptide intensity (Aiii). (B) Representative blots after agarose gel electrophoresis of denatured and reduced proteins extracted from sputum showing staining of all mucins with periodic acid-Schiff (PAS) staining and immunoblotting for MUC5AC and MUC5B (LCl = low-charge isoform; HCl = high-charge isoform). Note that the band pattern of the combined MUC5AC/MUC5B overlay (bottom panel) matches exactly with that in the PAS blot (top panel) for each sample. (C) Quantification of $\mathrm{HCl}$ and LCl of MUC5B from agarose gel electrophoresis blots. Statistics: box-and-whisker plots display median, interquartile ranges, and range; Mann-Whitney nonparametric test was used; ${ }^{\star \star \star \star} P<0.0001$. LFQ $=$ label-free quantification; tot $=$ total.

studied were in a range predicted to compress the PCL, slow mucus transport, and contribute to mucoobstructive disease pathogenesis. Indeed, significant associations were observed between mucus concentration and indices of disease severity, for example, $\mathrm{FEV}_{1}$ and HRCT, in patients with NCFB. These data are consistent with the nonlinear relationships between mucus concentration and mucus transportability (4) and indicate a role for mucus concentration in the mucoobstructive component of NCFB. Notably, NCFB sputum total mucin concentrations were $\sim 2$ times higher than sputum concentrations of sputum from highly obstructed subjects with COPD, consistent with the more severe bronchiectatic lung disease characteristic of NCFB versus COPD (19).

Analyses of individual secreted mucins in NCFB sputum revealed several key points. First, like previous reports, the sputum MUC5B concentration in healthy subjects was $\sim 10$-fold greater than MUC5AC (8). Second, consistent with elevated total mucins in NCFB, the concentrations of both major secreted airway mucins, that is, MUC5AC and MUC5B, were higher in NCFB than in healthy control subjects. As reported previously in COPD, the ratio of MUC5AC to MUC5B concentrations was elevated in sputum from patients with NCFB 
A

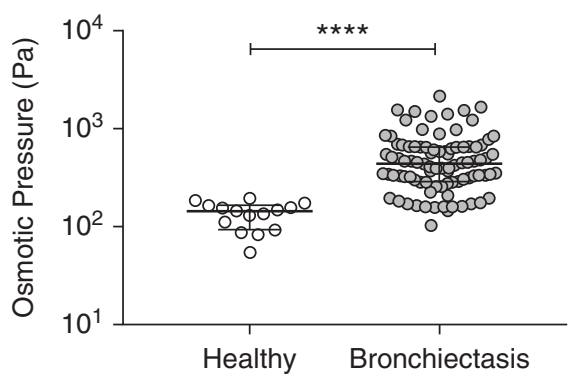

D

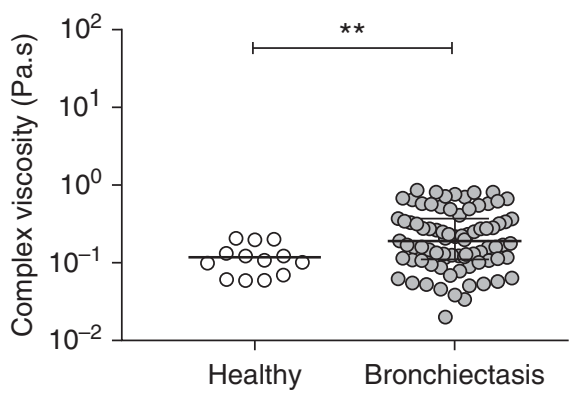

B

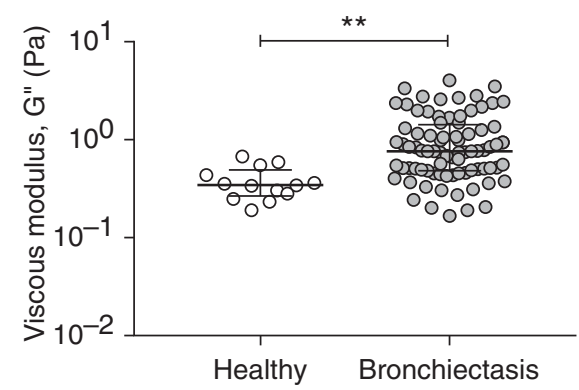

E

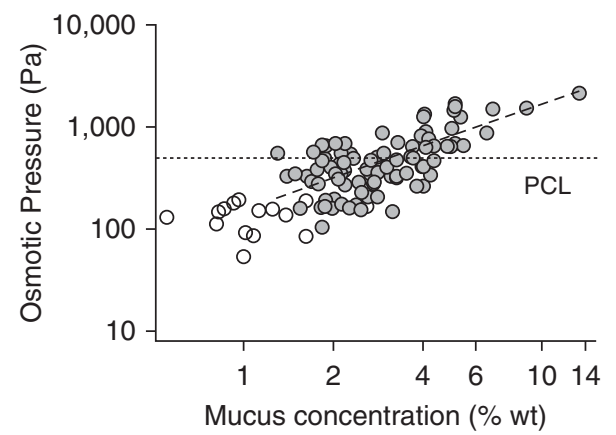

C

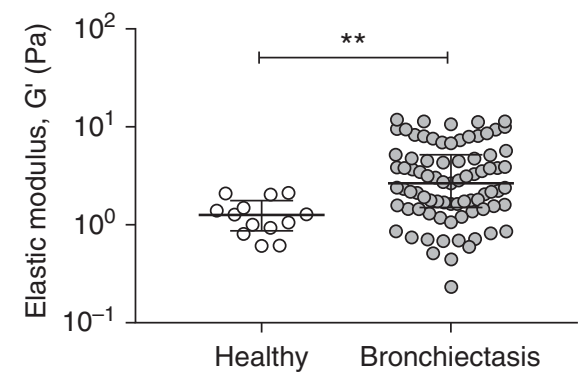

F

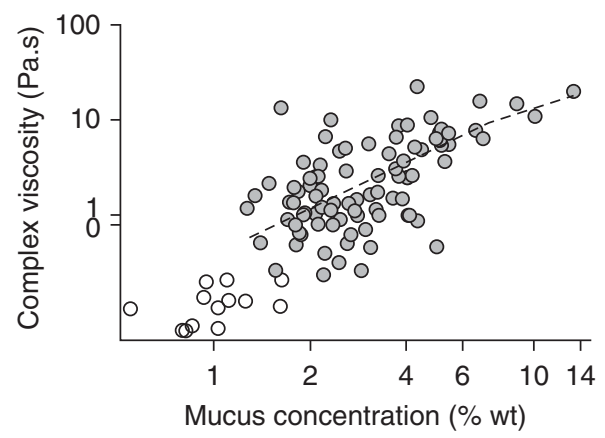

Figure 4. The biophysical properties of induced sputum in individuals with non-cystic fibrosis bronchiectasis (NCFB). (A) Osmotic pressure, (B) viscous moduli, $(C)$ elastic moduli, and $(D)$ complex viscosity of induced sputum were higher in individuals with NCFB (gray circles) than in healthy control subjects (white circles). The $(E)$ osmotic pressure (Spearman rho [95\% confidence interval] $=0.71$ [0.59-0.82], $P<0.001)$ and $(F)$ complex viscosity $(0.49[0.32-0.66], P<0.001)$ of induced sputum correlated significantly with mucus percent solids (NCFB: gray circles; control subjects: white circles). Dashed line/PCL = periciliary layer osmotic pressure. (A-D) Individual data points, median, and interquartile ranges are shown; Mann-Whitney nonparametric test was used. $n=99 ;{ }^{* *} P<0.01$ and ${ }^{\star \star \star \star} P<0.0001 . \mathrm{G}=$ viscous modulus; $w t=$ weight.

compared with control subjects (8). However, the concentration of MUC5B exceeded the concentration of MUC5AC in patients with NCFB. Thus, similar to COPD, NCFB is a MUC5B-dominated disease. Also like COPD, the MUC5B promoter polymorphism associated with increased MUC5B expression in IPF was not associated with NCFB or NCFB disease severity in the BLESS cohort (20).

We detected only very small concentrations of MUC2 in normal and NCFB sputa by mass spectroscopy. These data contrast to the Sibila and colleagues study that reported MUC2 was the dominant mucin in NCFB, MUC2 concentrations correlated with $P$. aeruginosa infection, and MUC5B was nondetectable in $96 \%$ of NCFB samples (10). We speculate that the discrepancies in results reflect methodologic deficiencies in the Sibila study, including: 1) sample ultracentrifugation with only the soluble fraction assayed, effectively removing the highly gelled mucin glycoproteins and underestimating mucin concentrations; and 2) use of commercial ELISA kits for the mucin measurements without verification of specificity or intactness of mucin epitopes (7). Our data using multiple independent physical and mass spectroscopy-based methods indicate that MUC5B and MUC5AC are the major secreted mucins in patients with NCFB.

Elevated sputum volumes with increased mucus concentrations in NCFB imply increased mucus and mucin production compared with healthy control subjects. We have previously reported that subjects with NCFB exhibit an increase in a broad spectrum of cytokines in BAL fluid (21). IL-1 $\beta$ is a major regulator of both MUC5B and MUC5AC mucin in CF airways (5), and both sputum IL- $1 \beta$ and the chemokine IL-8 positively correlated not only with sputum volume but also mucus concentration. These findings, combined with the associations of mucus concentration with human neutrophil elastase and matrix metalloproteinase, suggest that multiple inflammatory pathways participate in positive feedback cycles to drive increased mucin biosynthesis and, ultimately, mucus/mucin secretion (5).
Interestingly, $P$. aeruginosa infection was not associated with mucus concentration, suggesting that if bacteria also drive mucin secretion, anaerobes and Haemophilus influenzae may be sufficient.

Mucus concentration reflects the balance between mucin and fluid (hydration) transport rates. Typically, mucins are cosecreted with paracrine/autocrine factors, for example, purine nucleotides, that match fluid transport to mucin secretory rates $(3,22,23)$. As one test of the role of mucin hypersecretion as a contributor to raised NCFB mucus concentrations, MUC5B and MUC5AC RNA levels in bronchial biopsies were measured and found not raised in NCFB compared with healthy subjects. This observation was juxtaposed to the increased goblet cell numbers, secretory genes expressed in goblet cells, and increased intracellular mucin stores typically associated with increased sputum volume. Presumably, this disconnect reflects: 1) the importance of post-transcriptional regulation of mucin protein production rates; and/or 2) the failure to adequately adjust mucin RNA levels to mucin cell-specific housekeeping genes; and/or 3) that like 
A

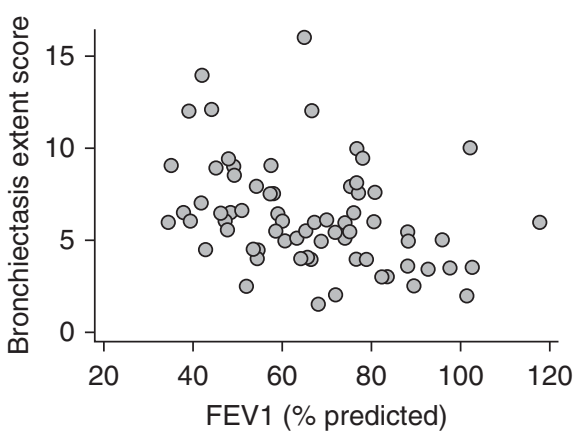

B

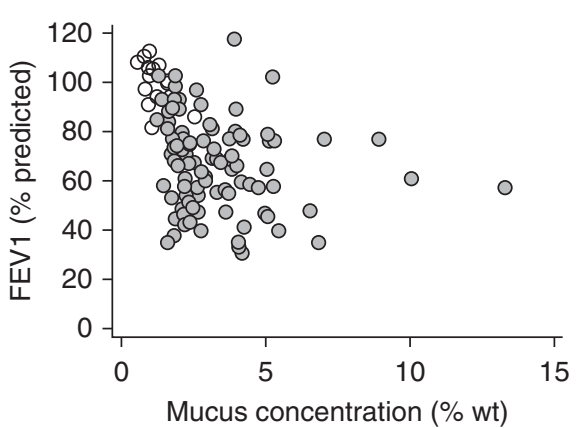

C

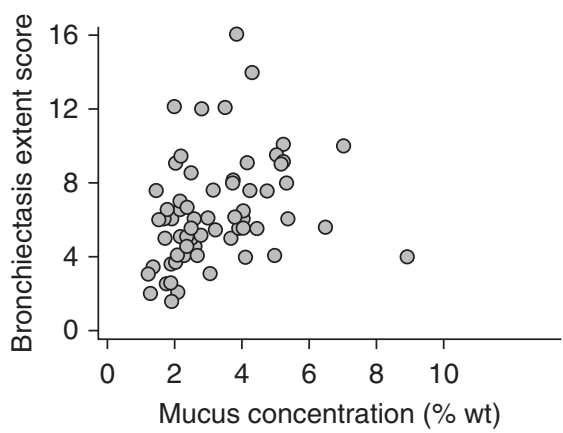

D

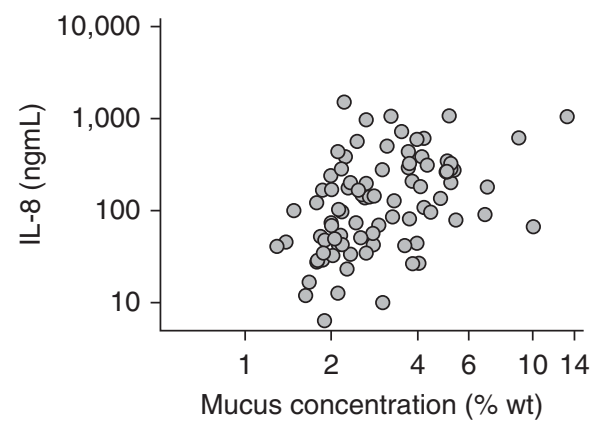

E

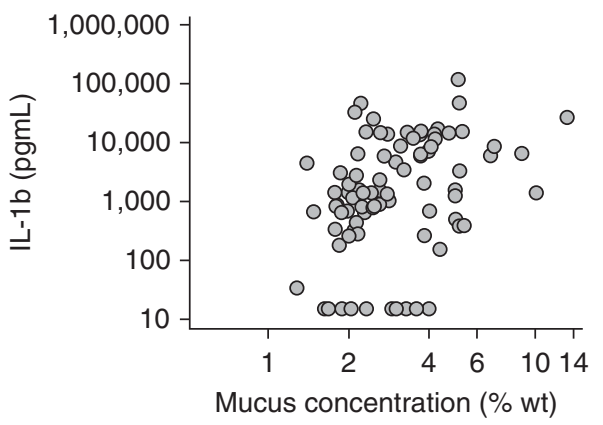

F

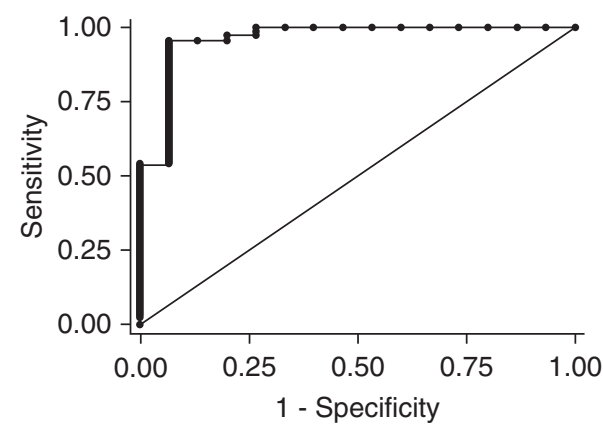

Figure 5. Association between mucus percent solids and clinical outcomes in BLESS (Bronchiectasis and Low-Dose Erythromycin Study) subjects with non-cystic fibrosis bronchiectasis (NCFB). (A) The high-resolution chest computed tomography bronchiectasis extent score significantly correlated with $\mathrm{FEV}_{1}$ (Spearman rho $[r][95 \%$ confidence interval $(\mathrm{Cl})]=0.40[-0.61$ to -0.19$\left.], P<0.001\right)$. (B) $\mathrm{FEV}_{1}$ significantly correlated inversely with mucus percent solids $(r[95 \% \mathrm{Cl}]=-0.22[-0.43$ to -0.01$], P=0.03)$, and $(C)$ mucus concentration correlated positively with high-resolution chest computed tomography extent scores $(r[95 \% \mathrm{Cl}]=0.41$ [0.19-0.63], $P<0.001)$. Mucus percent solids was significantly associated with the concentration of $(D) \mathrm{IL}-8(r[95 \% \mathrm{Cl}]=0.48$ [0.32-0.64], $P<0.001)$ and $(E) \mathrm{IL}-1 \beta(r[95 \% \mathrm{Cl}]=0.40$ [0.22-0.56], $P<0.001)$ in sputum. $(F)$ Ability of mucus concentration (percent solids) to diagnose NCFB. Area under the receiver operating characteristic $(\mathrm{ROC})$ curve $=0.9603$. Area under the ROC curve for total mucins in NCFB versus control cohorts $=0.949$ (see Figure E5). wt = weight.

$\beta$-ENaC mice, reduction in hydration, rather than mucin hyperproduction/secretion, drives the increase in mucus concentration $(24,25)$.

There are several mechanisms that may generate a mismatch between active airway transepithelial $\mathrm{Na}^{+}$absorption versus $\mathrm{Cl}^{-}$ secretion that would produce a deficiency of fluid on NCFB airway surfaces, that is, dehydration. Recent in vitro studies have reported that normal airways respond to infection-related bacterial/host materials with increased mucin production/secretion and disproportionately raised $\mathrm{Cl}^{-}$/fluid secretion, producing a reduction in mucus concentrations (26). Subjects with bronchiectasis without CFTR (cystic fibrosis transmembrane conductance regulator) mutations are reported to exhibit normal CFTR function, suggesting NCFB epithelium should respond similarly to epithelia from normal subjects (27). Three complementary mechanisms may account for abnormal fluid secretion in bronchiectatic airways. First, adherent mucus produces local epithelial hypoxia, which may inhibit CFTR transcription/activity and limit fluid secretion
$(28,29)$. Second, aberrant extracellular nucleotide/nucleoside-dependent airway hydration mechanisms have been reported in COPD that perturb the balance of $\mathrm{Na}^{+}$ absorption versus $\mathrm{Cl}^{-}$secretion and produce mucus hyperconcentration (30). Chronic injury and inflammation in NCFB may produce similar abnormalities. Third,

abnormal extracellular protease, for example, human neutrophil elastase, activation of $\mathrm{ENaC}$ activity has been reported (31), which may also tip the balance of fluid homeostasis toward absorption in NCFB. This latter mechanism is consistent with our data describing significant associations between sputum

Table 2. Correlation between Sputum Mucus Properties and Lung Function and Bronchiectasis Extent Score in Patients with Non-Cystic Fibrosis Bronchiectasis

\section{FEV $_{1}$ (\% Predicted)}

Solids, \%

Total mucins, $\mu \mathrm{g} / \mathrm{ml}$

MUC5AC/MUC5B

Sputum volume, $g$

Osmotic pressure, $\mathrm{Pa}$

Complex viscosity, $\mathrm{Pa} \cdot \mathrm{s}$

Definitions of abbreviations: $\mathrm{MUC5AC}=$ mucin $5 \mathrm{AC}$; $\mathrm{MUC5B}=$ mucin $5 \mathrm{~B}$

Data are presented as Spearman rho correlation coefficients (95\% confidence interval) $(n=99)$.

${ }^{*} P<0.05$.

${ }^{\dagger} P<0.001$

${ }^{\ddagger} P<0.01$. 
Table 3. Correlation between Sputum Mucus Properties and Inflammatory Markers in Patients with Non-Cystic Fibrosis Bronchiectasis

\section{IL-8 (ng/m)}

IL-1ß (pg/mI)

$0.48(0.32 \text { to } 0.64)^{\star}$
$0.36(0.18 \text { to } 0.55)^{\star}$
$0.49(0.14 \text { to } 0.84)^{\dagger}$
$0.26(0.04 \text { to } 0.48)^{\ddagger}$
$0.26(0.04 \text { to } 0.49)^{\ddagger}$
$0.32(0.11 \text { to } 0.54)^{\dagger}$
$-0.25(-0.46 \text { to }-0.03)^{\ddagger}$
$0.49(0.30 \text { to } 0.69)^{\star}$

$0.49(0.30 \text { to } 0.69)^{\star}$

$0.40(0.22 \text { to } 0.56)^{\star}$
$0.27(0.06 \text { to } 0.48)^{\star}$
$0.57(0.28 \text { to } 0.85)^{\dagger}$
$0.35(0.12 \text { to } 0.58)^{\dagger}$
$0.08(-0.14$ to 0.29$)$
$0.23(0.01 \text { to } 0.46)^{\ddagger}$
$-0.28(-0.49 \text { to }-0.07)^{\dagger}$
$0.46(0.26 \text { to } 0.65)^{\star}$

NE Activity $(\mu g / m)$
Solids, \%

Total mucins, $\mu \mathrm{g} / \mathrm{ml}$

MUC5AC/MUC5B

Sputum volume, $g$

Osmotic pressure, $\mathrm{Pa}$

Complex viscosity, $\mathrm{Pa} \cdot \mathrm{s}$

$\mathrm{FEV}_{1}, \%$ predicted

Bronchiectasis score

$0.47(0.30 \text { to } 0.63)^{\star}$
$0.29(0.10 \text { to } 0.48)^{\dagger}$
$0.45(0.18 \text { to } 0.72)^{\dagger}$
$0.29(0.08 \text { to } 0.51)^{\dagger}$
$0.15(-0.07$ to 0.37$)$
$0.21(-0.003$ to 0.44$)$
$-0.39(-0.58 \text { to }-0.19)^{\star}$
$0.56(0.36 \text { to } 0.76)^{\star}$

MMP Activity (AU/mI)

Definition of abbreviations: MMP = matrix metalloproteinase; MUC5AC = mucin 5AC; MUC5B = mucin 5B; NE = neutrophil elastase.

Data are presented as Spearman rho correlation coefficients (95\% confidence interval) $(n=99)$.

${ }^{\star} P<0.001$.

${ }^{\dagger} P<0.01$.

${ }_{\ddagger} P<0.05$.

concentrations of neutrophil elastase and matrix metalloproteinase and sputum mucus and mucin concentrations.

The severity of the BLESS cohort made searching for sputum biomarkers to describe NCFB severity difficult. The heterogeneity of disease within lungs of subjects with NCFB also complicates the utility of sputum as a biomarker. However, recent data suggest that mucus is only spontaneously expectorated as sputum when it is abnormally hyperconcentrated (32). Consequently, a single, but severely diseased (bronchiectatic) region with hyperconcentrated mucus can lead to production of sputum that may contain diagnostic information (32). This consideration, coupled to the severity of the BLESS population, likely contributed to the "excellent" area under the curve observed in the utility of ROC analyses of sputum percent solids to discriminate between NCFB versus control subjects. As disease progresses, more areas become bronchiectatic, and spirometry becomes abnormal. Interestingly, sputum volume, which might also be expected to reflect disease severity within the NCFB cohort, did not correlate with $\mathrm{FEV}_{1}$. However, modest associations of mucus percent solids with $\mathrm{FEV}_{1}$ were observed, suggesting NCFB disease progression may be associated with intensification of the processes that produce mucus hyperconcentration. This notion is consistent with observations that mucus percent solids and osmotic pressure also correlated with HRCT in BLESS subjects. These correlations mimic previous reports that total mucins were inversely associated with $\mathrm{FEV}_{1}$ in chronic bronchitis, where mucus hyperconcentration is also present (33). Collectively, these data suggest that mucus concentration may be an excellent biomarker for the presence of NCFB disease and a modest biomarker for NCFB disease extent/progression.

Although macrolides reduce exacerbations, reduce sputum volume, and improve lung function in patients with NCFB, their mechanisms of action remain unclear (34). Macrolides have been shown to have antimicrobial, including effects on $P$. aeruginosa quorum sensing (35), and immunomodulatory properties (36). In the BLESS trial, erythromycin induced a rapid and sustained decline in daily sputum volume (11). Our study was not designed to test whether erythromycin produced changes in sputum concentration or composition from baseline values. Hence, our study does add to mechanistic insights into macrolide mucoregulatory activities in NCFB. However, our study did reveal that HS sputum induction reduced sputum mucus concentrations by $\sim 25 \%$. These data suggest the HS may have a favorable mechanism of therapeutic action, that is, rehydrate/dilute hyperconcentrated mucus. Whether the likely short duration of action of inhaled HS in non-CF lung disease can produce therapeutic activity is unknown (37).

Strengths of our study include its setting within a large trial-based cohort with extensive clinical characterization, a healthy control comparator cohort, a replicate disease cohort, endobronchial samples, longitudinal data, and parallel measurements of microbial status and inflammation. There are also inherent limitations of our study. BLESS subjects were selected on the basis of high exacerbation frequency and are skewed toward a severe phenotype. Induced sputum samples were evaluated, as they provide reliable samples of both healthy and diseased airways, but we showed that induction produced modest sputum dilution. Rheology was performed on small aliquots that were subject to freeze-thaw, which had the potential to influence the biophysical data. The MUC5B SNP analysis was performed on only 101 patients with bronchiectasis, which is a small sample size for a polymorphism study. Finally, bronchial biopsies were obtained from subsegmental carinas, which may not reflect gene expression in diseased, that is, ectatic, airways.

In summary, similar to other mucoobstructive airway diseases, NCFB sputum exhibits elevated mucus percent solids, total and individual mucin concentrations, mucus osmotic pressures, and mucus viscoelastic moduli compared with sputum from healthy control subjects. The alterations in mucus properties appear to be influenced by the severity of airway inflammation, but not the presence of classical pathogens. The level of mucus concentration in patients with NCFB is within the range predicted to produce mucostasis and reductions in $\mathrm{FEV}_{1}$. These observations suggest that rehydration of NCFB airways may be a rational therapeutic strategy.

Author disclosures are available with the text of this article at www.atsjournals.org.

Acknowledgment: The authors dedicate this manuscript to the memory of the late Dr. David Serisier who devised and supervised the BLESS (Bronchiectasis and Low-Dose Erythromycin Study) trial. 


\section{References}

1. Whitwell F. A study of the pathology and pathogenesis of bronchiectasis. Thorax 1952;7:213-239.

2. Gonem S, Scadding A, Soares M, Singapuri A, Gustafsson P, Ohri C, et al. Lung clearance index in adults with non-cystic fibrosis bronchiectasis. Respir Res 2014;15:59.

3. Boucher RC. Muco-obstructive lung diseases. N Engl J Med 2019;380: 1941-1953.

4. Button B, Cai LH, Ehre C, Kesimer M, Hill DB, Sheehan JK, et al. A periciliary brush promotes the lung health by separating the mucus layer from airway epithelia. Science 2012;337:937-941.

5. Chen G, Sun L, Kato T, Okuda K, Martino MB, Abzhanova A, et al. IL-1 $\beta$ dominates the promucin secretory cytokine profile in cystic fibrosis. J Clin Invest 2019;129:4433-4450.

6. Horsley A, Rousseau K, Ridley C, Flight W, Jones A, Waigh TA, et al. Reassessment of the importance of mucins in determining sputum properties in cystic fibrosis. J Cyst Fibros 2014;13:260-266.

7. Henderson AG, Ehre C, Button B, Abdullah LH, Cai LH, Leigh MW, et al. Cystic fibrosis airway secretions exhibit mucin hyperconcentration and increased osmotic pressure. J Clin Invest 2014;124:3047-3060.

8. Kesimer M, Ford AA, Ceppe A, Radicioni G, Cao R, Davis CW, et al. Airway mucin concentration as a marker of chronic bronchitis. $N$ Engl J Med 2017;377:911-922.

9. Kirkham S, Kolsum U, Rousseau K, Singh D, Vestbo J, Thornton DJ. MUC5B is the major mucin in the gel phase of sputum in chronic obstructive pulmonary disease. Am J Respir Crit Care Med 2008;178: 1033-1039.

10. Sibila O, Suarez-Cuartin G, Rodrigo-Troyano A, Fardon TC, Finch S, Mateus EF, et al. Secreted mucins and airway bacterial colonization in non-CF bronchiectasis. Respirology 2015;20:1082-1088.

11. Serisier DJ, Martin ML, McGuckin MA, Lourie R, Chen AC, Brain B, et al. Effect of long-term, low-dose erythromycin on pulmonary exacerbations among patients with non-cystic fibrosis bronchiectasis: the BLESS randomized controlled trial. JAMA 2013;309:1260-1267.

12. Ramsey KA, Radicioni G, Hill D, Ehre C, Button B, Alexis NE, et al. Airways mucus pathogenesis in patients with non-cystic fibrosis bronchiectasis. Eur Respir J 2018;52:PA5049.

13. Ramsey KA, Radicioni G, Livengood S, Hill D, Ehre C, Button B, et al. Airways mucus pathogenesis in patients with non-cystic fibrosis bronchiectasis and primary ciliary dyskinesia [abstract]. Am J Respir Crit Care Med 2019;199:A5708.

14. Kirkham S, Sheehan JK, Knight D, Richardson PS, Thornton DJ. Heterogeneity of airways mucus: variations in the amounts and glycoforms of the major oligomeric mucins MUC5AC and MUC5B. Biochem J 2002;361:537-546.

15. Hill DB, Long RF, Kissner WJ, Atieh E, Garbarine IC, Markovetz MR, et al. Pathological mucus and impaired mucus clearance in cystic fibrosis patients result from increased concentration, not altered $\mathrm{pH}$. Eur Respir J 2018;52:1801297.

16. Meyerholz DK, Lambertz AM, Reznikov LR, Ofori-Amanfo GK, Karp PH, McCray PB Jr, et al. Immunohistochemical detection of markers for translational studies of lung disease in pigs and humans. Toxicol Pathol 2016;44:434-441.

17. Groneberg DA, Eynott PR, Oates T, Lim S, Wu R, Carlstedt I, et al. Expression of MUC5AC and MUC5B mucins in normal and cystic fibrosis lung. Respir Med 2002;96:81-86.

18. Okuda K, Chen G, Subramani DB, Wolf M, Gilmore RC, Kato T, et al. Localization of secretory mucins MUC5AC and MUC5B in normal/healthy human airways. Am J Respir Crit Care Med 2019;199: 715-727.

19. Murphy TF, Brauer AL, Eschberger K, Lobbins P, Grove L, Cai X, et al. Pseudomonas aeruginosa in chronic obstructive pulmonary disease. Am J Respir Crit Care Med 2008;177:853-860.
20. Hunninghake GM, Hatabu H, Okajima Y, Gao W, Dupuis J, Latourelle $\mathrm{JC}$, et al. MUC5B promoter polymorphism and interstitial lung abnormalities. N Engl J Med 2013;368:2192-2200.

21. Chen AC, Martin ML, Lourie R, Rogers GB, Burr LD, Hasnain SZ, et al. Adult non-cystic fibrosis bronchiectasis is characterised by airway luminal Th17 pathway activation. PLoS One 2015;10: e0119325.

22. Kreda SM, Okada SF, van Heusden CA, O’Neal W, Gabriel S, Abdullah $\mathrm{L}$, et al. Coordinated release of nucleotides and mucin from human airway epithelial Calu-3 cells. J Physiol 2007;584:245-259.

23. Kreda SM, Seminario-Vidal L, van Heusden CA, O'Neal W, Jones L, Boucher RC, et al. Receptor-promoted exocytosis of airway epithelial mucin granules containing a spectrum of adenine nucleotides. J Physiol 2010;588:2255-2267.

24. Mall M, Grubb BR, Harkema JR, O'Neal WK, Boucher RC. Increased airway epithelial $\mathrm{Na}+$ absorption produces cystic fibrosis-like lung disease in mice. Nat Med 2004;10:487-493.

25. Livraghi-Butrico A, Grubb BR, Wilkinson KJ, Volmer AS, Burns KA, Evans $\mathrm{CM}$, et al. Contribution of mucus concentration and secreted mucins Muc5ac and Muc5b to the pathogenesis of mucoobstructive lung disease. Mucosal Immunol 2017;10:395-407.

26. Abdullah LH, Coakley R, Webster MJ, Zhu Y, Tarran R, Radicioni G, et al. Mucin production and hydration responses to mucopurulent materials in normal versus cystic fibrosis airway epithelia. $A m \mathrm{~J}$ Respir Crit Care Med 2018;197:481-491.

27. Bienvenu T, Sermet-Gaudelus I, Burgel PR, Hubert D, Crestani B, Bassinet L, et al. Cystic fibrosis transmembrane conductance regulator channel dysfunction in non-cystic fibrosis bronchiectasis. Am J Respir Crit Care Med 2010;181:1078-1084.

28. Zheng W, Kuhlicke J, Jäckel K, Eltzschig HK, Singh A, Sjöblom M, et al. Hypoxia inducible factor-1 (HIF-1)-mediated repression of cystic fibrosis transmembrane conductance regulator (CFTR) in the intestinal epithelium. FASEB J 2009;23:204-213.

29. Bartoszewska S, Kamysz W, Jakiela B, Sanak M, Króliczewski J, Bebok Z, et al. miR-200b downregulates CFTR during hypoxia in human lung epithelial cells. Cell Mol Biol Lett 2017;22:23.

30. Anderson WH, Coakley RD, Button B, Henderson AG, Zeman KL, Alexis NE, et al. The relationship of mucus concentration (hydration) to mucus osmotic pressure and transport in chronic bronchitis. Am J Respir Crit Care Med 2015;192:182-190.

31. Caldwell RA, Boucher RC, Stutts MJ. Neutrophil elastase activates near-silent epithelial $\mathrm{Na}+$ channels and increases airway epithelial $\mathrm{Na}+$ transport. Am J Physiol Lung Cell Mol Physiol 2005;288: L813-L819.

32. Button B, Goodell HP, Atieh E, Chen YC, Williams R, Shenoy S, et al. Roles of mucus adhesion and cohesion in cough clearance. Proc Natl Acad Sci USA 2018;115:12501-12506.

33. Henderson AG, Anderson WH, Ceppe A, Coakley RD, Button B, Alexis $\mathrm{NE}$, et al. Mucus hydration in subjects with stable chronic bronchitis: a comparison of spontaneous and induced sputum. COPD 2018;15: 572-580.

34. Wu Q, Shen W, Cheng H, Zhou X. Long-term macrolides for non-cystic fibrosis bronchiectasis: a systematic review and meta-analysis. Respirology 2014;19:321-329.

35. Burr LD, Rogers GB, Chen AC, Hamilton BR, Pool GF, Taylor SL, et al. Macrolide treatment inhibits Pseudomonas aeruginosa quorum sensing in non-cystic fibrosis bronchiectasis: an analysis from the bronchiectasis and low-dose erythromycin study trial. Ann Am Thorac Soc 2016;13:1697-1703.

36. Principi N, Blasi F, Esposito S. Azithromycin use in patients with cystic fibrosis. Eur J Clin Microbiol Infect Dis 2015;34:1071-1079.

37. Bennett WD, Wu J, Fuller F, Balcazar JR, Zeman KL, Duckworth H, et al. Duration of action of hypertonic saline on mucociliary clearance in the normal lung. J Appl Physiol (1985) 2015;118: 1483-1490. 